DOI 10.5216/ia.v46i3.61325

\title{
A REESTRUTURAÇÃO PRODUTIVA E O FINANCIAMENTO DA EDUCAÇÃO: UMA VISÃO HISTÓRICA DOS EFEITOS E CONSEQUÊNCIAS DAS DETERMINAÇÕES MATERIAIS NA PERIFERIA DO SISTEMA
}

\author{
Henry Bill Mc Quade Junior \\ Universidade Federal de Santa Catarina (UFSC), Florianópolis, Santa Catarina, Brasil
}

\begin{abstract}
Resumo: O presente artigo pretende responder as seguintes perguntas: como a reestruturação produtiva e a ofensiva neoliberal de fins do século XX prejudicam a capacidade de financiamento da educação por parte dos Estados nacionais, em especial na América Latina? E quais os efeitos sociais derivados deste movimento? Nos valemos de uma análise histórica que articule universal, particular e singular, estrutura e superestrutura, em busca de compreender os problemas quanto à capacidade do financiamento da educação na América Latina, em especial no Brasil. Pensamos que a Emenda Constitucional (EC) 95 é a consequência da incapacidade do Estado, frente à pressão da dívida pública e à austeridade fiscal, ou seja, efeitos da ideologia neoliberal, a qual direciona o fundo público para a esfera financeira e privada.
\end{abstract}

Palavras-chave: Marxismo. Educação. Estado. História.

INTRODUÇÃO

Ao buscar responder como a reestruturação produtiva e a ofensiva neoliberal de fins do século XX prejudicam a capacidade de financiamento da educação por parte dos Estados nacionais, em especial na América Latina, e quais os efeitos sociais derivados deste movimento, optamos por uma análise materialista histórica e dialética.

Para tanto, estruturaremos metodologicamente nosso trabalho do seguinte modo, a saber: iniciaremos com uma análise histórica dos precedentes da crise de acumulação produtiva dos anos 70, fundamentalmente da crise do que se convencionou chamar de crise do Estado de Bem Estar Social, com o esgotamento da "época de ouro" do capitalismo, e a consequente reestruturação produtiva e a sua ofensiva neoliberal, na intenção de garantir novos níveis de expansão e acumulação do capital, agora sobre outras bases. Ou seja, uma análise histórica que busca entender as transformações nas bases materiais de produção e reprodução social do capital, para em seguida derivar as influências que essas alterações, de cunho estrutural, provocam dialeticamente na capacidade dos Estados em gerir e amenizar as contradições da expansão/acumulação do capital e seus efeitos sociais nefastos, afetando, com isso, o financiamento social do Estado, em especial o financiamento da educação, e colocando parte dos sistemas de educação sob tutela da gestão do capital privado ao transformar a educação em mercadoria. Acreditamos que tal estrangulamento se consolida com a E.C. 95, enquanto cristalização do projeto de sucateamento e privatização da educação pública. 


\section{OS ANTECEDENTES HISTÓRICOS DA REESTRUTURAÇÃO}

Para entender o movimento de fins do século $\mathrm{XX}$, em relação à reestruturação produtiva e à crise do Estado de Bem Estar Social, devemos fazer uma imersão histórica para reconstruir as mediações necessárias para desnudar as reais consequências sociais, em especial na educação, e o verdadeiro mote desse movimento.

A gênese do sistema capitalista se fundamentou na ideia de um Estado mínimo, ou seja, um Estado que deveria (1) se resguardar a garantir a propriedade privada, (2) os contratos entre compra e venda de mercadorias realizados entre "iguais" perante a lei Estado de Direito, (3) e mediante a força policialesca, garantir um mínimo de ordem para o progresso material, entenda-se expansão e acumulação de capital. Assim, a não intervenção econômica por parte do Estado, o Laissez-faire, deveria deixar sob a responsabilidade das forças de mercado, oferta e procura, a orquestração do sistema de trocas nacionais e internacionais, e a iniciativa privada seria a chave mestra para responder com a oferta de mercadorias e serviços.

A expansão desenfreada desse sistema voraz, cuja lógica de maximização de lucros, independente das condições sociais de exploração do trabalho, se aliou ao imperialismo enquanto forma de atuação internacional dos Estados na busca da acumulação. Esses dois movimentos amalgamados geraram uma grande convulsão social', principalmente nos países centrais, levando à criação, nesses Estados, de um mínimo de proteção social, materializadas em leis que protegiam, mesmo que de maneira precária, as populações locais. Um bom exemplo disso é a Constituição de Weimar na Alemanha, uma das primeiras constituições sociais do mundo capitalista, já sinalizando para a falência dos ideais liberais. Outros aspectos são os constantes enfrentamentos entre os Estados imperialistas na arena internacional na busca de novos mercados consumidores e novas fontes de matérias-primas, cuja expansão desenfreada coincidirá com a eclosão da Primeira Guerra Mundial, e a consequente eclosão da Segunda Guerra, partes de um mesmo movimento, assim como nos ensina Hobsbawm, o período da "Grande Guerra", consequência de um mesmo movimento, das lutas Interimperialistas e da ganância capitalista.

Além disso, vale lembrar que no período entre guerras, a Crise de 29 elucidou dois movimentos importantes, a saber: (1) a crise foi vista como uma crise de superprodução, isto é, uma crise de realização da mercadoria, pois devido às condições precárias de grande parte da classe trabalhadora explorada, o consumo de mercadorias não acompanhava os grandes níveis de produção de um sistema industrial baseado na produção em massa, e a desregulamentação do capital favoreceu para o desenrolar de uma das primeiras grandes crises financeiras da economia mundial; (2) outro ponto importante foi a forma que os Estados encontraram para sair da Crise, isto é, esse movimento mostrou ao mundo que o Liberalismo clássico não se sustentava somente ao deixar a economia na responsabilidade pura do mercado, e o Estado deveria intervir de forma maciça nas economias nacionais para impedir um crack geral da economia mundial. Um bom exemplo disso foi o New Deal norte-americano, uma das primeiras manifestações do que, anos mais tarde, seria conhecido como keynesianismo. No Brasil, uma das primeiras ações econômicas do governo Vargas foi a queima de café, para 
impedir a drástica desvalorização dessa mercadoria, principal produto da pauta de exportação nacional, garantindo assim um mínimo de lucratividade para a classe produtora de café e a continuidade do funcionamento da economia nacional, mesmo que de maneira precária.

Com o fim da "Grande Guerra", em 1945, o sistema internacional passou por uma profunda reestruturação. Foram criadas as Instituições Internacionais, como a ONU, e seus braços de ação, como o FMI (Fundo Monetário Internacional), o BM (Banco Mundial), o GATT (Acordo Geral sobre Tarifas e Taxas), entre outros, cuja finalidade era monitorar as relações políticas e econômicas para garantir um mínimo de estabilidade internacional para a expansão e acumulação do capital. Outros dois movimentos foram importantes nesse momento: primeiro, o acordo de Bretton Woods, o qual coloca uma paridade na conversibilidade do ouro em dólar, o que se convencionou chamar de "padrão ouro-dólar", garantindo um mínimo de estabilidade e controle no sistema monetário internacional; e o segundo movimento é o Plano Marshall, um bloco maciço de investimentos norte-americanos, em dólar, nas economias devastadas com a guerra para a reconstrução das mesmas, contribuindo para e recuperação das economias locais, provocando assim uma dolarização da economia mundial e uma alta demanda de produtos industriais, em especial, norte-americanos. Outro fato importante foi o confronto entre capitalismo e socialismo, representados pelos Estados hegemônicos, Estados Unidos da América e União Soviética, respectivamente, o que criou um cenário competitivo entre os dois modelos de sociedade vigentes na época.

Todos esses fatores em conjunto, somados às teses keynesianas da importância do Estado para o aumento da demanda agregada no capitalismo, deram luz ao que ficou conhecido como "era de ouro" e ao Estado de Bem Estar Social. Nesse novo momento da economia mundial, os Estados garantiram a construção de um amplo "guarda-chuva" de proteção aos trabalhadores, assim como uma série de direitos fundamentais como saúde, educação, previdência social, garantias trabalhistas, entre outras, que deram um fôlego extra para a expansão e a acumulação do capitalismo a nível mundial, com um consequente aumento do consumo e da produção capitalista, garantindo altas taxas de rentabilidade ao capital investido na esfera produtiva.

Além das bases lançadas pelo Estado e pelas novas Instituições Internacionais para sustentar/amparar esse novo ciclo de crescimento econômico, a estrutura produtiva alicerçada no taylorismo-fordismo, e em uma nova tecnologia dos bens de consumo duráveis, isto é, geladeiras, fogões, televisores, rádios, automóveis, entre outras mercadorias, ajudou a provocar esse período de crescimento econômico, pois grande parte das populações ainda não tinha acesso a esses bens, e o consumo das classes trabalhadoras foi um dos principais motores desse surto de crescimento.

Esse movimento aconteceu, principalmente, nas economias centrais do sistema capitalista, ao passo que na periferia do sistema, em especial na América Latina, os países dessa região lutavam para alcançar o tão sonhado desenvolvimento econômico. Nesse âmbito, a CEPAL (Comissão Econômica para a América Latina e o Caribe) foi de extrema importância; os trabalhos de Prebisch, e seu conceito de "tendência à deterioração dos termos de troca", além de várias correntes de pensamento que interpretavam a situação de dependência, garantiram a emergência de políticas de industrialização dos países marginais por meio da Substituição das Importações (SI), garantindo assim a consolidação, mesmo que precária, de um pátio industrial nacional, diminuindo o 
coeficiente de importação com a produção do similar nacional.

No Brasil, assim como na maioria dos países latino-americanos, dada a influência direta dos EUA, o caminho escolhido foi o da democracia capitalista, e a década de 1950 foi fundamental para a construção do parque industrial nacional. $\mathrm{Na}$ realidade brasileira, assistiu-se à implementação do I Plano Nacional Desenvolvimentista (I PND) de Juscelino Kubitschek, o seu "50 anos em 5", com um grande auxílio do capital internacional e das grandes empresas capitalistas, principalmente as montadoras de automóveis e outros bens de consumo duráveis. A III internacional comunista havia lançado, anos antes, uma visão "etapista" do desenvolvimento das forças produtivas capitalistas como condição sine qua non para a revolução proletária, fazendo com que até os próprios Partidos Comunistas ( $\mathrm{PC}$ 's), no Brasil e nos demais países da América Latina, optassem pela via da associação da classe operária com a burguesia em prol da construção de um projeto nacional (conciliação de classe), instauração da democracia burguesa e a industrialização nacional, para assim possibilitar, no futuro, a revolução operária.

O processo de industrialização brasileira começou a alterar as características nacionais. Assistimos a um "boom" da urbanização, com o inchaço das grandes cidades, a mudança do Distrito Federal, um aumento do proletariado nacional e sua constituição como classe, a organização cada vez maior dos sindicatos e dos movimentos sociais, que reivindicavam garantias mínimas de condições de vida e trabalho para a maioria excluída da população, e uma ação mais afirmativa do Estado nacional.

O problema da terra, principalmente da estrutura fundiária do Brasil, permaneceu inalterado, com grandes concentrações de terra e uma gigantesca desigualdade de renda, ampliando ainda mais o abismo entre os que têm e os que não têm, e por mais organizada que se encontrasse a classe trabalhadora, as políticas redistributivas e a reforma agrária não encontravam respaldo do apelo popular no poder público.

Contudo, no início da década de 60 , com a ascensão inesperada ao poder de Jango (João Goulart), o qual tinha certas afinidades com a classe trabalhadora e, por esse motivo, tentou constituir uma política de reformas institucionais, iniciou-se um processo de participação popular, "acenando com a possibilidade de ruptura com a ordem burguesa" (SAVIANI, 2011, p. 313). O clima do nacional desenvolvimentismo, que permeou a ideologia nacional de 30 em diante, até fins da década de 50 e início de 60, começava, a partir de então, a ter uma coloração de esquerda, principalmente graças à vitória da revolução chinesa e cubana a nível internacional, o aumento da massa de trabalhadores urbanos e a organização da massa campesina no plano nacional e continental.

Esse movimento acabou contaminando o debate em torno da educação, que começou a desenhar novos caminhos. Os principais embates entre a pedagogia tradicional, principalmente de orientação católica, e a pedagogia nova, que ganhou força especialmente após 32, com a publicação do "Manifesto dos Pioneiros da Educação Nova", começou a ganhar novos contornos, graças às demandas do processo de industrialização e à pressão dos principais intelectuais do campo educativo, aglutinados ao redor da causa da "modernização humanista da educação". Os intelectuais da 
educação nova chegaram, nas décadas de 50-60, a transformar, em grande parte, os preceitos da educação tradicional religiosa, cuja adaptação se fez indispensável para a continuação de sua atuação em âmbito nacional, e o Estado ganhou destaque quanto ao financiamento da educação.

Um dos principais nomes da educação na década de 50 foi o de Anísio Teixeira, um dos grandes defensores da pedagogia nova, cuja atuação ganhou destaque na defesa de uma escola gratuita que favorecia o desenvolvimento da nação e de sua população, com um financiamento garantido pelos estados e pela união, engenharia de arrecadação criada por ele e que será a base do FUNDEF e do FUNDEB nas décadas de 1990 e 2000. Eduardo Azevedo, Florestan Fernandes, Álvaro Vieira Pinto, Nelson Sodré, entre outros, também tiveram uma participação de destaque em prol de um novo modelo educacional mais humano, alguns desses mais à esquerda que outros, como é o caso de Florestan.

Nesse contexto foi promulgada a Lei n. 4024, a primeira LDB nacional, em 20 de dezembro de 1961, entrando em vigor no ano seguinte. A lei previa um processo de descentralização da educação, a nível estadual, e indicava a necessidade da criação de um Conselho Federal de Educação (CFE), além de prever a criação de um Plano Nacional de Educação (PNE).

Todos esses acontecimentos convergiram para uma ação mais efetiva na intenção da classe dominante em manter seus privilégios e a condição de dominados da maioria da população, em âmbito interno, e que, se fizessem valer os interesses do capital externo, efetivando assim em abril de 1964 um Golpe de Estado, que instaurou no Brasil uma ditadura militar extremamente violenta e impositiva, exilando e cassando grande parte dos pensadores críticos e líderes dos movimentos sociais e políticos de esquerda. Um movimento de "contrarrevolução", imprimindo um modelo excludente de desenvolvimento nacional, ligado diretamente aos interesses das classes dominantes a nível internacional, e promovendo uma reviravolta educacional por meio da pedagogia tecnicista e do conceito de formação de um "capital humano" qualificado para a promoção do tão sonhado desenvolvimento nacional nos moldes do capitalismo periférico e dependente, intenções cristalizadas principalmente na Lei 5.692/71.

No tocante ao financiamento, ampliou-se as bases de atuação do Estado, mas não universalizou-se a educação e, com a reviravolta de 71, a educação se convertia em carro chefe para formação de mão de obra, minimamente qualificada, para contribuir com o desenvolvimento econômico, ficando de lado uma formação de caráter humanista, amplo, com bases científicas, optando-se assim por uma formação aligeirada para o trabalho e não para um desenvolvimento social, mas sim econômico.

Estes acontecimentos marcaram a realidade brasileira, mas não se restringiram somente ao Brasil. Em toda a América Latina assistiu-se a um movimento de imposição violenta, por meio de ditaduras militares, de um projeto específico de sociedade, a capitalista - o "americam way of life", sob a ideologia do desenvolvimento dependente e associado, e o Estado controlava este movimento com rédeas curtas, restringindo a atuação dos movimentos sociais, e até mesmo a participação na cena política de partidos contrários a esse modelo de sociedade. A ditadura de Pinochet, no Chile, transformou o país em laboratório do continente para a imposição dos ditames do neoliberalismo, e teve como exemplo o início da privatização do sistema educacional chileno. 
Vale a pena salientar, com o exposto até aqui, que fica claro que a sociedade brasileira e latino-americana, chegaram atrasadas na cena histórica das revoluções burguesas ${ }^{2}$ ocorridas entre os séculos XVIII e XIX na Europa e nos EUA, e que, até mesmo o momento internacional, no qual se tentou consolidar tal movimento, o da década de 60 -70, o próprio sistema de acumulação capitalista e o Estado de Bem Estar Social já apresentavam claramente sinais de desgaste, e os ideólogos do neoliberalismo já vinham preparando sua ofensiva, principalmente com base nas ideias de Friedman e Hayek.

\section{A CRISE ESTRUTURAL DO CAPITAL E A RESTRUTURAÇÃO PRODUTIVA E DO ESTADO}

É em fins de 60 e início de 70 que podemos encontrar a chave para todo o movimento da reestruturação produtiva e do Estado. Alguns acontecimentos desse período nos ajudam a compreender sobre quais bases serão lançadas as transformações na base material e da organização política e social, e como tais transformações irão afetar a realidade mundial, em especial dos países da América Latina, assim como condicionar o desenvolvimento das populações locais em nome da valorização do capital.

A ruptura unilateral por parte dos EUA do padrão ouro em 71, deixando a economia mundial sob o regime das taxas de juros e câmbio flutuantes, juntamente com a crise do petróleo de 73 , criaram um cenário internacional propício para a eclosão da "financeirização" da economia mundial. O Plano Marshall já tinha criado uma dolarização, principalmente nos mercados europeus, e os países dessa região não tiveram alternativa a não ser aceitar o sistema de reservas baseados em dólares e de uma moeda fiduciária. A ida de bancos e empresas norte-americanas para a europa, possibilitaram a criação de um mercado bancário off-shore, que, com as grandes receitas geradas pelo choque do petróleo (petrodólares), ofertavam empréstimos a juros baixos devido à abundância de capital nesses mercados.

Foi nesse momento que grande parte dos países latino-americanos contraiu dívidas altíssimas em nome do desenvolvimento econômico. No Brasil, o II PND dos militares foi um bom exemplo disso.

No entanto, como já destacado anteriormente, nesse momento a economia mundial apresentava um panorama de estagflação, de diminuição do ritmo de produção e consumo, e os níveis das taxas de lucro começavam a despencar. O Estado começava a encontrar problemas para financiar seus custos sociais. Isso porque o padrão tecnológico da segunda revolução industrial já estava esgotado e o consumo vinha gradualmente sendo reduzido. Além disso, a abundância de produtos, consequência do modelo produtivo do taylorismo-fordismo, e uma taxa de desemprego crescente, impunham a necessidade de outro padrão de organização produtiva, pois uma crise de superprodução já se avizinhava. O modelo a seguir como saída desse estrangulamento já funcionava no Japão, uma economia pequena que não podia suportar uma produção em massa, por isso, desenvolveu um modelo de produção que se voltava para a demanda e não para a formação de estoque, baseada no sistema Just in time e kanban, fruto das inovações tecnológicas e de comunicação/informação (toyotismo). 
A crise que se apresentou na década de 70 teve características de uma crise estrutural, de acordo com Mészáros, por ser universal, global, permanente e rastejante. Altas taxas de desemprego, retração das taxas de acumulação produtiva, crise ambiental etc., são alguns dos fatores que vão levar o capital a optar pela esfera financeira para se valorizar, mesmo que de forma fictícia e apoiada, mesmo que em última instância na produção industrial. Essa valorização se concentrou, especialmente, nos mercados de câmbio, juros e os empréstimos aos Estados, cuja capacidade de arcar com o custo dos benefícios sociais ficava cada vez mais debilitada, demandando assim uma estratégia de financiamento baseada no lançamento de títulos públicos nos mercados financeiros, inaugurando o que Chesnais irá chamar de "ditadura dos credores".

O segundo choque do petróleo, e o choque dos juros promovido pela economia norte-americana, em 79, lançaram as bases para a retomada da hegemonia dos EUA. $O$ panorama de crise empurrou os EUA a promover uma estratégia para retomar a dianteira tecnológica e de acumulação de capital. O aumento da ordem de $300 \%$ nas taxas de juros norte-americana, fez com que uma grande massa de capitais flutuantes migrassem para o interior da economia dos EUA, o que favoreceu, em um segundo momento, uma inversão maciça de investimentos em pesquisa e desenvolvimento tecnológico, fato que favoreceu a eclosão da terceira revolução industrial e tecnológica, a microeletrônica, a comunicação - internet e celulares, e os computadores (informática), levando a economia dos EUA a retomar a dianteira no processo de liderança econômica, devido a um novo surto de consumo destes novos produtos. Ao contrário do modelo de produção anterior, não se busca uma ampliação do consumo de massa, mas sim uma intensificação do consumo, tendo as mercadorias um tempo de vida útil reduzido. Esse desenvolvimento favoreceu também a consolidação da reestruturação produtiva, pois a rapidez e fluidez das informações possibilitou a concretização do novo modelo, que se espalhou pelo mundo na intenção de encontrar os menores custos produtivos, garantindo uma retomada na lucratividade na esfera produtiva.

Por outro lado, as economias que se endividaram durante a década de 70, em especial as economias latino-americanas, sofreram com um aumento catastrófico de suas dívidas, o que coincidiu com a crise da dívida dos anos 80 , a hiperinflação e a estagnação destas economias (principalmente com a moratória mexicana de 1982). A retomada da lucratividade produtiva não significou que essa esfera de valorização voltasse a ser hegemônica como nos anos dourados. Pelo contrário, o ciclo produtivo, nesse novo momento da economia mundial, ficou subordinado à esfera financeira, nesse momento, o principal lócus de valorização do capital. Vale a pena lembrar que foi criada uma série de mecanismos que garantiram a supremacia financeira, como os derivativos financeiros, os fundos de pensão, os mercados futuros, entre outros, que colocaram a onda financeira como principal local de valorização do capital e a esfera produtiva ficou subordinada a esses ditames financeiros.

No âmbito dos Estados, os ataques ao Estado de Bem Estar Social, realizados pela ofensiva neoliberal (principalmente apoiada nas teses de Hayek), vão aos poucos desconstruindo este tipo de atuação dos Estados, conferindo a esses uma nova forma de atuação, cuja principal característica é garantir uma arena favorável para a valorização financeira e um controle social mais efetivo. As principais demandas do neoliberalismo foram: a liberalização dos fluxos de capital; a privatização dos setores produtivos sobre o controle do Estado; a flexibilização das leis trabalhistas; a redução dos gastos sociais, 
como na saúde, educação, previdência, entre outros. Isto é, uma retirada gradual do Estado da economia, e uma volta as leis de mercado como regente da vida social, o que significa a transformação da totalidade da vida social em mercadorias e serviços ofertados pela iniciativa privada, como educação, previdência, saúde, entre outros e o início de uma avassaladora expropriação de diversos matizes.

Nesse momento, a atuação dos Organismos Internacionais (ou Instituições Internacionais) foi de grande influência para a conduta dos Estados, em especial, os Estados periféricos como os Estados latino-americanos. Esse objetivo se cristalizou no Consenso de Washington, cuja intenção principal era a de garantir que os Estados latinoamericanos seguissem à risca a cartilha neoliberal, engessando o Estado na sua atuação social, fazendo com que ele priorizasse o pagamento de suas dívidas internacionais e garantisse a entrada e atuação do capital externo privado em suas economias (principalmente na busca de valorização financeira de curto prazo, fruto das altas taxas de juros praticadas pelos Estados latino-americanos). Na educação, documentos apoiados e financiados pelos organismos internacionais, como o Banco mundial, Unesco, entre outras, ditou as diretrizes para o campo, como exemplo podemos citar o Relatório Delors de 1996.

No âmbito produtivo, com a adoção dos preceitos do neoliberalismo, o capital pode escolher quais as melhores opções para instalar seus parques produtivos, ou seja, as melhores ofertas para a redução de custos, seja pela oferta de mão de obra abundante e barata, seja pelas isenções fiscais oferecidas pelos Estados, seja pela proximidade das fontes de matérias-primas, ou por todas essas garantias somadas, as quais favorecem uma intensificação da exploração do trabalho e uma alta lucratividade ao capital em um sistema de produção mundializado.

No âmbito do trabalho, o que assistimos é uma precarização e intensificação do trabalho, fatos que podem ser observados pela flexibilização e terceirização do trabalho, a retirada das proteções legais do trabalhador, aumento da previdência privada, entre outras estratégias utilizadas para garantir uma maior extração da mais valia (mais valor) do trabalhador e rentabilidade do capital por meio de operações financeiras privadas com os fundos de pensão dos trabalhadores. No Brasil, as reformas trabalhistas do governo Temer, a E.C. 95, o projeto da reforma da previdência, entre outras, são materializações de tais políticas.

Estão dadas as bases do novo momento socioeconômico. Tentamos sintetizar as principais transformações nas bases materiais da produção e reprodução da vida material dos seres humanos, assim como mostrar como são alteradas também as bases institucionais e políticas para o controle social, e para garantir a imposição de um modelo societal em prol do capital. Faremos agora nossas considerações finais.

\section{CONSIDERAÇÕES FINAIS}

Indicamos no início deste trabalho os nossos questionamentos, a saber: como a reestruturação produtiva e a ofensiva neoliberal de fins do século XX prejudicaram a capacidade de financiamento da educação por parte dos Estados nacionais, em especial na América Latina? E quais os efeitos sociais derivados desse movimento? 
JUNIOR, H. B. Mc Q.

Acreditamos ter conseguido mostrar o desmonte do Estado, associado às transformações no âmbito produtivo, e a ideologia do neoliberalismo, são fatos que retiram o Estado como garantidor de bens essenciais, como saúde, educação, previdência, entre outros. Fica claro que esse desmonte acabou com qualquer possibilidade do Estado garantir, por meio de investimentos sociais, uma educação, gratuita, laica, e de qualidade, pois o estrangulamento gerado pela crise da dívida impediu que esses gastos fossem prioridade do Estado, principalmente pelas imposições realizadas pelas Ol's, como o $\mathrm{CW}$, e, ao tornar tudo mercantilizável, a iniciativa privada será um dos principais ofertadores destes serviços e mercadorias. A E.C. 95 é a constatação dessa falência.

Ou seja, as transformações nas bases materiais vão dialeticamente afetar a sociedade como um todo, em especial no financiamento da educação por parte do Estado, cuja nova forma de atuação prejudicou a maioria das populações que eram excluídas, dadas as características de concentração de renda desses movimentos, isto é, ampliação do abismo social entre ricos e pobres, e a educação ficou jogada às traças da esfera privada, pois tem acesso quem tem condições, e a maioria deveria se contentar com uma educação pública sucateada pelo abandono.

Os efeitos sociais são nefastos, pois uma população que cada vez menos tem acesso a um conhecimento científico de qualidade, humano, crítico, não tem possibilidade de ler sua realidade e a realidade do mundo, isto é, não pode compreender/apreender o mundo do qual fazem parte e não conseguem contribuir para um debate coletivo para melhorar suas condições de vida e de todas as populações do planeta. Não podem fazer frente a esse sistema desumano, pois não são oferecidas as ferramentas para um projeto de sociedade alternativo, um outro mundo - o conhecimento científico crítico.

Este trabalho, com suas lacunas e limites, teve a intenção de contribuir para o debate, para uma leitura crítica da evolução histórica de nossa realidade, articulando o universal, particular e singular, no âmbito da educação, para abrir possibilidades da retomada de um projeto educativo que busque fornecer uma das condições para a emancipação social das amarras do capital. Estamos cientes de que, dadas as condições de nosso momento histórico, o Estado como financiador deste outro projeto de educação é fundamental e, como parte da sociedade, os pesquisadores não podem se abster de contribuir para o debate de uma melhor condição de educação de suas populações, fornecendo as condições para a construção de um projeto alternativo de sociabilidade, fundado em uma educação gratuita, laica, crítica e de qualidade, consolidando assim, a construção de novas utopias, novos caminhos rumo a outro mundo possível.

Artigo recebido em: 21/11/2019

Aprovado para publicação em: 16/11/2020

PRODUCTIVE RESTRUCTURING AND EDUCATION FINANCING: EFFECTS AND CONSEQUENCES OF MATERIAL DETERMINATIONS ON THE PERIPHERY OF THE SYSTEM; A HISTORICAL INSIGHT 
ABSTRACT: This article aims to answer the following questions: How do the productive restructuring and neoliberal offensive of the late twentieth century undermine the ability of national states to finance education, especially in Latin America? And what are the social effects derived from this movement? We use a historical analysis that articulates universal, particular and singular, structure and superstructure, in an attempt to understand the problems regarding the financing capacity of education in Latin America, especially in Brazil. We think that the Constitutional Amendment (E.C.) 95 is the consequence of the incapacity of the state, faced with the pressure of public debt and fiscal austerity, that is, the neoliberal ideology which directs the public fund to the financial and private sphere.

KEYWORDS: Marxism. Education. State. Story.

\section{REESTRUCTURACIÓN PRODUCTIVA Y FINANCIACIÓN DE LA EDUCACIÓN: EFECTOS Y CONSECUENCIAS DE DETERMINACIONES MATERIALES EN LA PERIFERIA DEL SISTEMA; UNA VISIÓN HISTÓRICA}

RESUMEN: Este artículo tiene como objetivo responder las siguientes preguntas: ¿Cómo la reestructuración productiva y la ofensiva neoliberal de finales del siglo XX socavan la capacidad de los estados nacionales para financiar la educación, especialmente en América Latina? ¿Y cuáles son los efectos sociales derivados de este de la educación en América Latina, especialmente en Brasil. Creemos que la Enmienda movimiento? Utilizamos un análisis histórico que articula la estructura y superestructura universal, particular y singular, en un intento por comprender los problemas relacionados con la capacidad financiera Constitucional (E.C.) 95 es la consecuencia de la incapacidad del estado, ante la presión de la deuda pública y la austeridad fiscal, es decir, la ideología neoliberal que dirige el fondo público a la esfera financiera y privada.

PALABRAS CLAVE: Marxismo. Educacion. Estado. Historia.

\section{NOTAS}

1 - Vale lembrar que o nascimento das ideias socialistas deita suas raízes neste processo de combate das contradições entre o capital e o trabalho, originando uma concepção de mundo que vislumbrava mudanças na forma de organização produtiva e social, almejando a emancipação social e a libertação do homem da exploração deste sobre ele mesmo.

2 - A própria formação nacional está diretamente ligada ao processo de colonização, sendo que se priorizou no Brasil e na América Latina um modelo de colônia de exploração, cujo desenvolvimento histórico limitou a emancipação nacional e inseriu toda essa região de forma atrasada e dependente na Divisão Internacional do Trabalho, reservando a essas nações um pequeno pedaço nas riquezas geradas na economia mundial e uma ínfima participação nas grandes decisões de política internacional. Uma forma de capitalismo dependente e periférico. Além de que a história da América Latina só começa a ser contada como uma etapa do desenvolvimento comercial europeu, entrando no jogo condicionada as vontades das metrópoles e aos desejos de acumulação de uma burguesia nascente. 
JUNIOR, H. B. Mc Q.

REFERÊNCIAS

CHESNAIS, F. A globalização e o curso do capitalismo de fim-de-século. Trad. Catherine Marie Mathieu, Economia e Sociedade, Campinas, (5): 1-30, dez. 1995.

HOBSBAWM, E. J. Era dos extremos: um breve do séulo vinte: 1914-1991. Trad. Marcos Santarrita; revisão técnica Maria Célia Paoli. São Paulo, ed. Companhia das Letras, 1995. primeira reimpressão.

LÖWY, M. Ideologias e ciências social: elementos para uma análise marxista. São Paulo, Cortez, 1992.

MARX, K.; ENGELS, F. A ideologia alemã (I Feuerbach). Tad. José Carlos Bruni e Marco Aurélio Nogueira. Hucitec, São Paulo, 1984.

MARX, K. Contribuição à crítica da economia política. Trad. e Introd. Florestan Fernandes. São Paulo, ed. Expressão Popular, 2008. segunda edição.

MARX, K. Manuscritos econômico-filosóficos e outros textos escolhidos. São Paulo, Nova Cultural, 1978. (Coleção Os Pensadores).

MARX, K. O Capital: crítica da economia política - livro l: o processo de produção do capital. Trad. Rubens Enderle. 2.ed. São Paulo, Boitempo, 2017.

MÉSZÁROS, I. A educação para além do capital. Trad. Isa Tavares. São Paulo, Boitempo, 2005.

MÉSZÁROS, I. A teoria da alienação em Marx. Trad. Isa Tavares. São Paulo, Boitempo, 2006.

MÉSZÁROS, I. Para além do capital: rumo a uma teoria da transição. Trad. Paulo Cezar Castanheira, Sérgio Lessa. 1. ed. revista. São Paulo, Boitempo, 2011.

PRADO, J. C. Clássicos sobre a revolução brasileira. Caio Prado Junior e Florestan Fernandes. São Paulo, Expressão Popular, 2007.

SAVIANI, D. História das ideias pedagógicas no Brasil. Campinas, Autores Associados, 2011.

Henry Bill Mc Quadr Junior: Possui graduação em Relações Internacionais - Faculdades de Campinas (2008) e mestrado em Educação pela Universidade do Sul de Santa Catarina (2015). Doutorando do Programa de Pós Graduação em Educação - PPGE, UFSC. É membro do Grupo de Estudos e Pesquisa em Ontologia Crítica - GEPOC na UFSC. Tem experiência na área de Educação, Filosofia, Relações Internacionais, 
Sociologia, atuando principalmente no seguinte tema: marxismo, ontologia, América Latina.

Orcid: https://orcid.org/0000-0001-8865-0507

E-mail: hbquade@smail.com

Este periódico utiliza a licença Creative Commons Attribution 3.0, para periódicos de acesso aberto (Open Archives Initiative - OAI). 